\title{
RTK-GPS positioning by TV audio-MPX-data broadcast in Japan
}

\author{
Hiromune Namie*, Akio Yasuda, and Koji Sasano \\ Tokyo University of Mercantile Marine, and Asahi National Broadcasting Co., Ltd., Japan
}

(Received December 31, 1999; Revised May 18, 2000; Accepted May 18, 2000)

\begin{abstract}
RTK-GPS is a satellite positioning system which provides instant and accurate positions. The ranging error to the satellite from a user GPS antenna determined by the phase measurement of the carrier waves from the GPS satellites is of the order of mms. Thus an accuracy of a few $\mathrm{cm}$ can be easily obtained. The system is easier to operate than a traditional survey system such as the 'Total Station'. Hence it has been used for many applications in Japan. It is necessary, however, to provide a fast data communication link for the transmission of carrier phase data from a reference station located at a known position, to a user receiver. A radio communication device with low power, is commonly used because it requires no license. However the data transmission area is generally limited to just several hundred meters in radius from the reference station. The authors have investigated RTK-GPS positioning with several different lengths of baseline using data transmission via TV audio-MPX-data broadcast, and evaluated its validity. The carrier phase data is transmitted from the reference receiver at the Tokyo University of Mercantile Marine, to the experimental station of the Asahi National Broadcasting Company, by public phone line with data rate 9,600 bps. The data, which when multiplexed into TV audio, was then disseminated with the rate of about $8 \mathrm{kbps}$ from the Tokyo Tower. The data transmission delay in this system appeared random between 0.740 and $1.317 \mathrm{~s}$, of which the difference $(0.577 \mathrm{~s})$ corresponds to the transmission time of 32 blocks of multiplexed data. Positioning was tried at several fixed points with different lengths of baseline $(0-21 \mathrm{~km})$. Tests proved that the accuracy became worse as the length of baselines became longer. The $2 \mathrm{drms}$ height are less than the $2.5 \mathrm{~cm}$, and 'Fix' solution success rates are more than $98 \%$, for shorter baselines less than $10 \mathrm{~km}$ in length.
\end{abstract}

\section{Introduction}

RTK-GPS (Real Time Kinematic GPS) is a real time satellite positioning system. The range to the satellite from a user GPS antenna determined by the phase measurement of the carrier waves from the GPS satellites is accurate to the $\mathrm{mm}$ level. Thus an accuracy of the order of a few cms can be easily obtained in $2 \mathrm{drms}$. The system is easier to operate than a traditional survey system such as the 'Total Station'. Many applications of RTK-GPS have been investigated in Japan (Namie et al., 1996, 1999).

RTK-GPS needs a fast data communication link for the carrier phase data transmission from a reference station located at a known position, to a user receiver. In Japan a low power radio communication device is usually used because it dose not require a license. However, the data transmission area is inevitably limited to just several hundred meters in radius from the reference station. It is hard for users to bear the burden of operating expensive GPS receivers. Furthermore it is technically difficult to establish a reference station, whose position is to be obtained to an accuracy less than one $\mathrm{cm}$. Hence RTK-GPS users in Japan have desired the development of a flexible and less expensive dissemination service.

*Present address: Department of Electrical and Electronic Engineering, National Defense Academy, 1-10-20 Hashirimizu, Yokosuka-City 2398686 .

Copy right (C) The Society of Geomagnetism and Earth, Planetary and Space Sciences (SGEPSS); The Seismological Society of Japan; The Volcanological Society of Japan; The Geodetic Society of Japan; The Japanese Society for Planetary Sciences.
The authors have investigated RTK-GPS positioning at several fixed points with different lengths of baseline (0$21 \mathrm{~km}$ ), using the carrier phase data transmission via the present TV audio-MPX-data broadcast, and have evaluated its validity.

\section{System Outline \\ 2.1 TV audio band}

The TV audio-MPX-data broadcast can disseminate the carrier phase data for many users across a wide area. It can receive the data using ordinary TV antennas, and can transmit the data as fast as $16 \mathrm{kbps}$.

Figure 1 shows the frequency spectrum of the TV audio band. $f_{H}$ is the horizontal scanning frequency, 15.734264 $\mathrm{kHz}$. There are two sub-carriers, in addition to the audio main channel and sub-channel for stereophonic and bilingual broadcasting. A wide frequency region is reserved for the data transmission. The $4.5 f_{H}$ sub-carrier is modulated by MSK to allow a rate of $16 \mathrm{kbps}$, as in our experiment.

\subsection{TV audio-MPX-data format}

Figure 2 shows the format for the data transmitted by TV audio-MPX-data broadcast. The GPS carrier phase data for every second are inserted in the data section, horizontally. They are sent out vertically every 32 blocks to minimize the effect of burst noise error. The errors are detected and corrected by horizontal checking code, CRC (Cyclic Redundancy Check) and CHC (Check Code). So the practical data transmission rate is $7,985.3 \mathrm{bps}$. It takes $0.577 \mathrm{~s}$ to transfer the data of 32 blocks. (The data transmission period is 16 


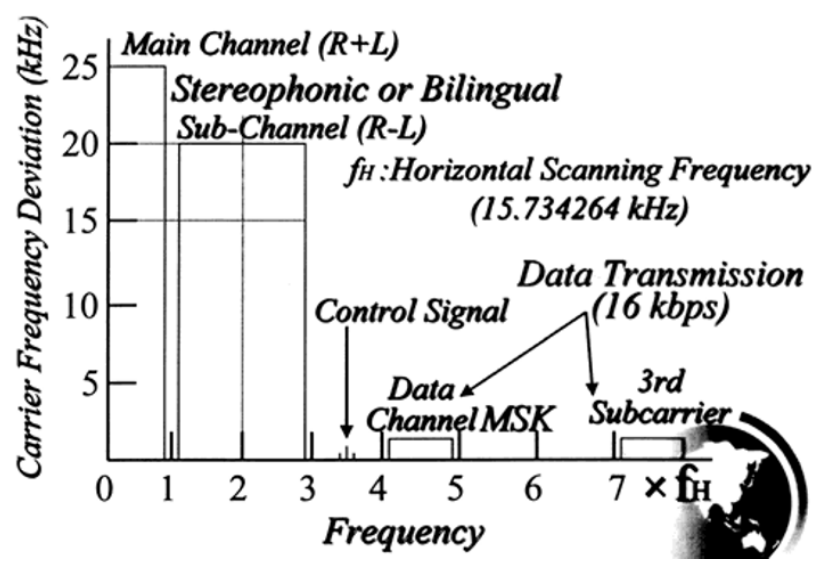

Fig. 1. Frequency spectrum of TV audio band.

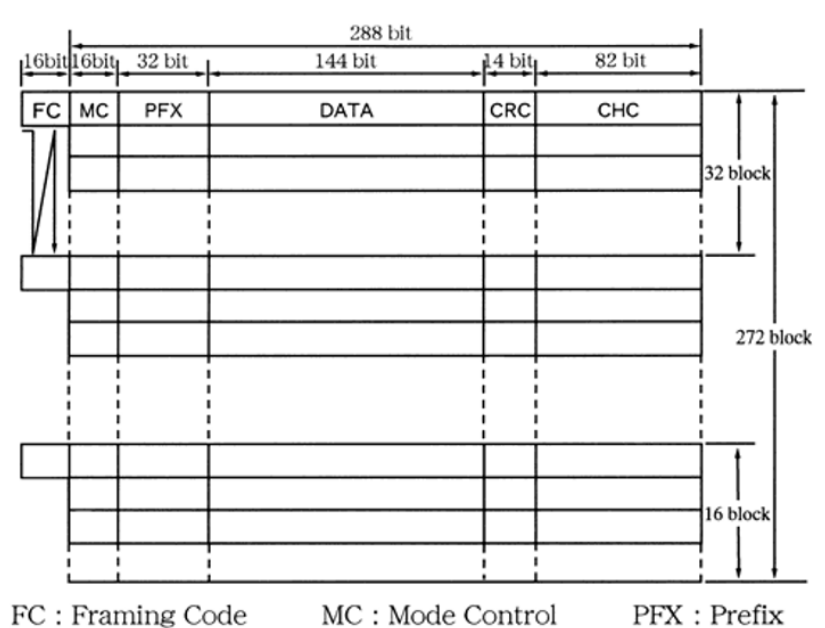

Fig. 2. Format of the data transmitted by TV audio-MPX-data broadcast.

bits $+(288$ bits/packet $) \times 32$ blocks $/ 16 \mathrm{kbps}=0.577 \mathrm{~s}$.

\subsection{Carrier phase data transmission format}

The format of the carrier phase data is Trimble CMR (Compact Measurement Record), defined and published by Trimble Navigation Limited at ION GPS-96. The volume of CMR data is about $1 \mathrm{kbit} / \mathrm{set}$, which is the average of about 30 minutes' data transmitted every second by a Trimble 4000SSi. On the other hand, RTCM SC-104 (version2.1) defines the Message Type 18, 19 for the carrier phase data transmission format. The format requires transmission of about $4 \mathrm{kbit} / \mathrm{set}$ every second. Compared with CMR, the format is inefficient for transmitting data. It is expected that RTCM will publish soon a more efficient format, version 3.0.

Most RTK-GPS receivers accept data only if they are transmitted and processed in the format developed by their own manufacturers. The publication of the proprietary format by a private company like Trimble is to be applaued. It may lead to standardization of the carrier phase transmission format in the not too distant future.

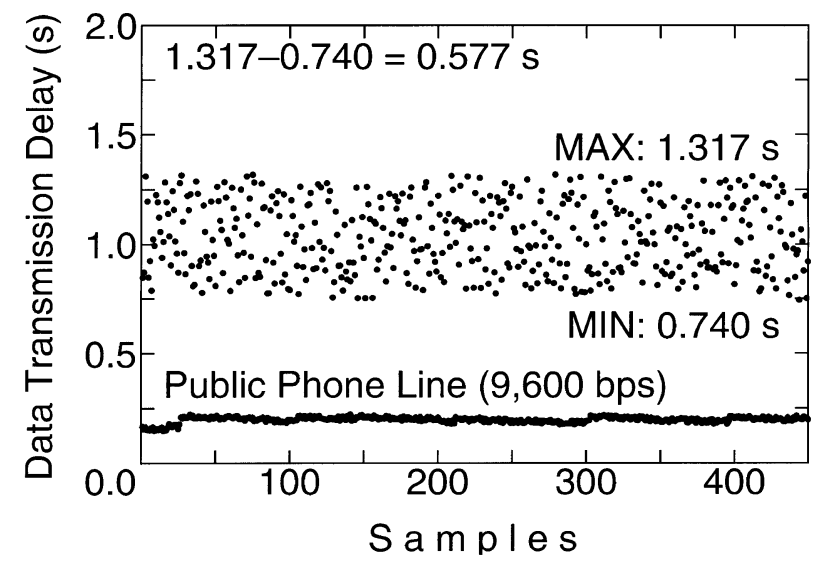

Fig. 3. Data transmission time.

\section{Data Transmission Delay}

First, the authors tried to measure the data transmission delay and evaluate the accuracy of positioning for several fixed points with different lengths of baseline.

RTK-GPS is required to give real time performance. The GPS receivers used in our experiment are the Trimble Navigation 4000SSE and 4000SSi. They determine the position from a combination of the carrier phase data transmilted by the reference station and the data user reciver collected at the same time. The system works best if the data transmission delay is less than $2 \mathrm{~s}$. The nominal positioning accuracy is $2 \mathrm{~cm}$ plus $2 \mathrm{ppm}$ of the baseline length, within a radius of about $10 \mathrm{~km}$ from the reference station.

The delays were measured between the head of carrier phase data output from the reference GPS receiver, and the same head of data input to user's 4000SSi, using a universal counter 5313 A (resolution: 50 ns) by Hewlett-Packard Co., Ltd.

Figure 3 shows an example of the time series of delay measurement by TV audio-MPX-data broadcast and by public phone line. The delay is not distributed randomly between 0.740 and $1.317 \mathrm{~s}$. And the difference $(0.577 \mathrm{~s})$ corresponds to the transmission time of 32 blocks of the audio-MPX-data. The carrier phase data was transmitted from the reference receiver to the experimental station of the Asahi National Broadcasting Company by public phone line with data rate of 9,600 bps. It is confirmed that the delay is well below $2 \mathrm{~s}$.

\section{RTK-GPS at Several Fixed Points}

Figure 4 shows the experimental configuration of RTKGPS positioning testing. The authors tried positioning at several fixed points with different lengths of baseline.

Figure 5 shows GPS antennas located on the roof of the experimental vehicle. The carrier phase data was transmitted from the reference receiver to the experimental station of the Asahi National Broadcasting Company by public phone line with data rate of 9,600 bps. The data, which were multiplexed into TV audio, were disseminated with a data rate of about $8 \mathrm{kbps}$ from the Tokyo Tower.

Figure 6 shows an example of the horizontal distribution of horizontal positioning and a temporal variation in height for 


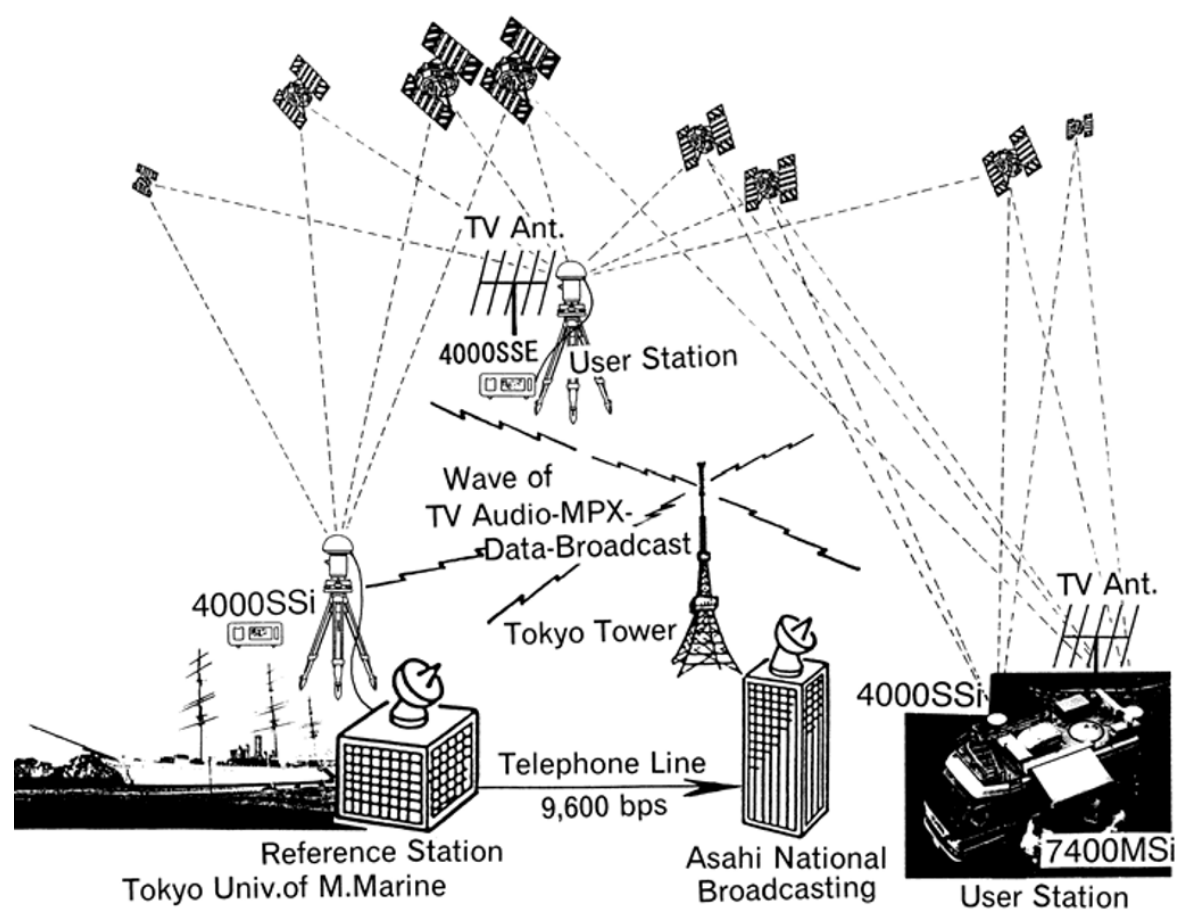

Fig. 4. Experimental configuration.

Table 1. Positioning result.

Trimble navigation CMR carrier phase data transmission format

\begin{tabular}{ccccc}
\hline Base line & Positioning time & Fix solution rate & $2 \mathrm{drms}$ & Altitude $\sigma$ \\
\hline Z B L & 5.1 hours & $99.3 \%$ & $0.19 \mathrm{~cm}$ & $0.11 \mathrm{~cm}$ \\
$20 \mathrm{~m}$ & 5.8 hours & $99.1 \%$ & $0.91 \mathrm{~cm}$ & $0.89 \mathrm{~cm}$ \\
$10 \mathrm{~km}$ & 1.5 hours & $98.0 \%$ & $1.96 \mathrm{~cm}$ & $2.47 \mathrm{~cm}$ \\
$21 \mathrm{~km}$ & 0.7 hours & $93.5 \%$ & $2.12 \mathrm{~cm}$ & $3.71 \mathrm{~cm}$ \\
\hline
\end{tabular}

RTCM carrier phase data transmission format

\begin{tabular}{ccccc}
\hline Base line & Positioning time & Fix solution rate & 2 drms & Altitude $\sigma$ \\
\hline $20 \mathrm{~m}$ & 8.8 hours & $93.6 \%$ & $1.43 \mathrm{~cm}$ & $1.20 \mathrm{~cm}$ \\
$4 \mathrm{~km}$ & 8.8 hours & $96.7 \%$ & $1.57 \mathrm{~cm}$ & $1.88 \mathrm{~cm}$ \\
\hline
\end{tabular}

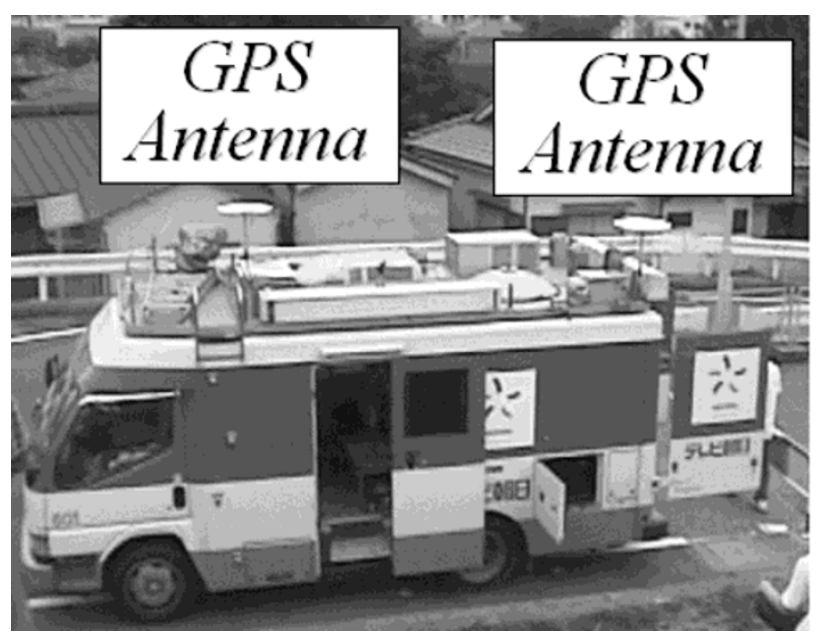

Fig. 5. Experimental vehicle. a baseline length of $20 \mathrm{~m}$ using the RTCM data transmission format and the 4000SSE receiver. The positioning accuracy were $1.43 \mathrm{~cm}$ in $2 \mathrm{drms}$ and $1.20 \mathrm{~cm}$ in S.D. of height. The 'Amibiguity Fix' solution rate is $93.6 \%$ (every second) for 8.8 hours positioning.

Table 1 shows the positioning result at several fixed points with different lengths of baseline using the RTCM and Trimble CMR carrier phase data transmission format. It is confirmed that as the lengths of baseline become longer the accuracy is worse. However the $2 \mathrm{drms}$ and S.D. in height are smaller than $2.5 \mathrm{~cm}$ with lengths of baseline less than $10 \mathrm{~km}$.

\section{Conclusions}

The authors have tried RTK-GPS positioning at several fixed points with different lengths of baseline, using carrier phase data transmitted in RTCM and Trimble CMR data formats, to test RTK-GPS carrier phase data transmitted by TV 


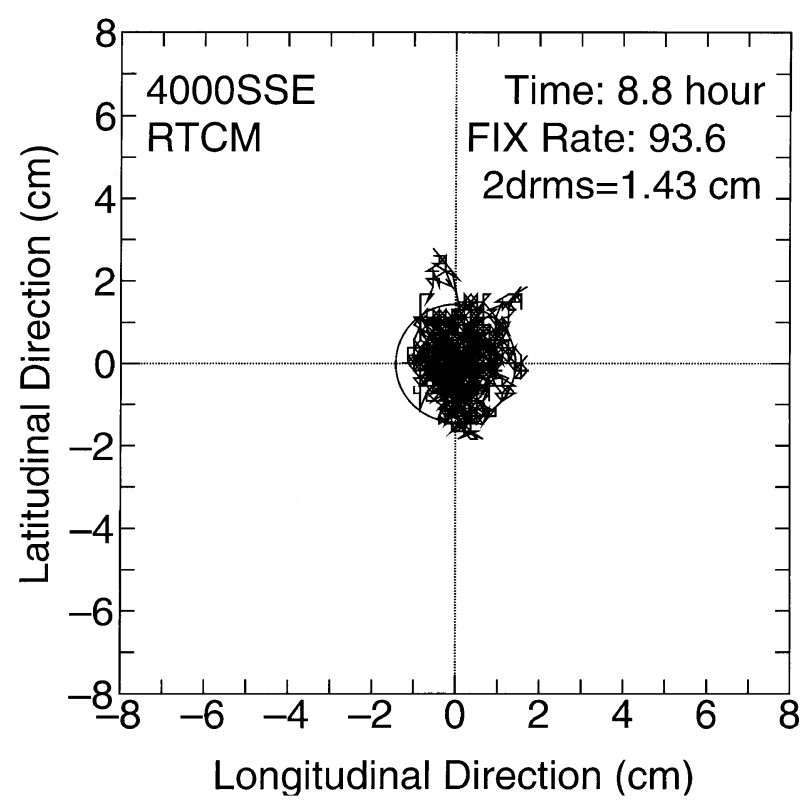

Horizontal Distribution

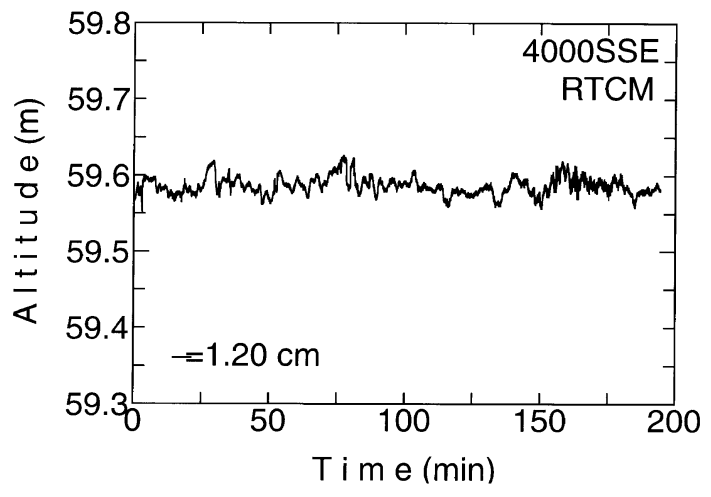

Temporal variation in Height

Fig. 6. Positioning distribution (base line: $20 \mathrm{~m}$ ).

audio-MPX-data dissemination. The tests shows that 2 drms is of the few $\mathrm{cm}$ level, and it was proved that the positioning system could operate satisfactorily. The present experiment was organized to conduct basic research into carrier phase data dissemination by TV waves. The regular service will commence soon for RTK-GPS/GLONASS positioning by the Asahi National Broadcasting Company.

Acknowledgments. The authors wish to thank Mr. Takashi Tanaka of LSI Japan for his help.

\section{References}

Okamoto, O., H. Tsuboi, H. Namie, and A. Yasuda, Application of RTK-GPS to Immersion of Caisson, International Symposium No. 117 on GraGeoMar96, pp. 704-711, 1996.

Namie, H., N. Tanaka, and A. Yasuda, RTK-GPS Positioning in Japan by GPS-Based Control Station via DMCA Mobile Radio Communication System, Proceedings of 1999 National Technical Meeting ION, pp. 495$503,1999$.

H. Namie (e-mail: nami@nda.ac.jp), A. Yasuda, and K. Sasano 